\title{
Correction to: Particulate Matter and Black Carbon in the Brahmaputra Valley of Northeast India: Observations and Model Simulation
}

\author{
B. S. Murthy, ${ }^{1}$ R. Latha, ${ }^{1}$ R. Srinivas, ${ }^{1}$ and G. Beig ${ }^{1}$
}

\section{Correction to: Pure Appl. Geophys. https://doi.}

$$
\text { org/10.1007/s00024-020-02590-1 }
$$

Unfortunately, Fig. 5 has been published incorrect. Please find the corrected Fig. 5 below:
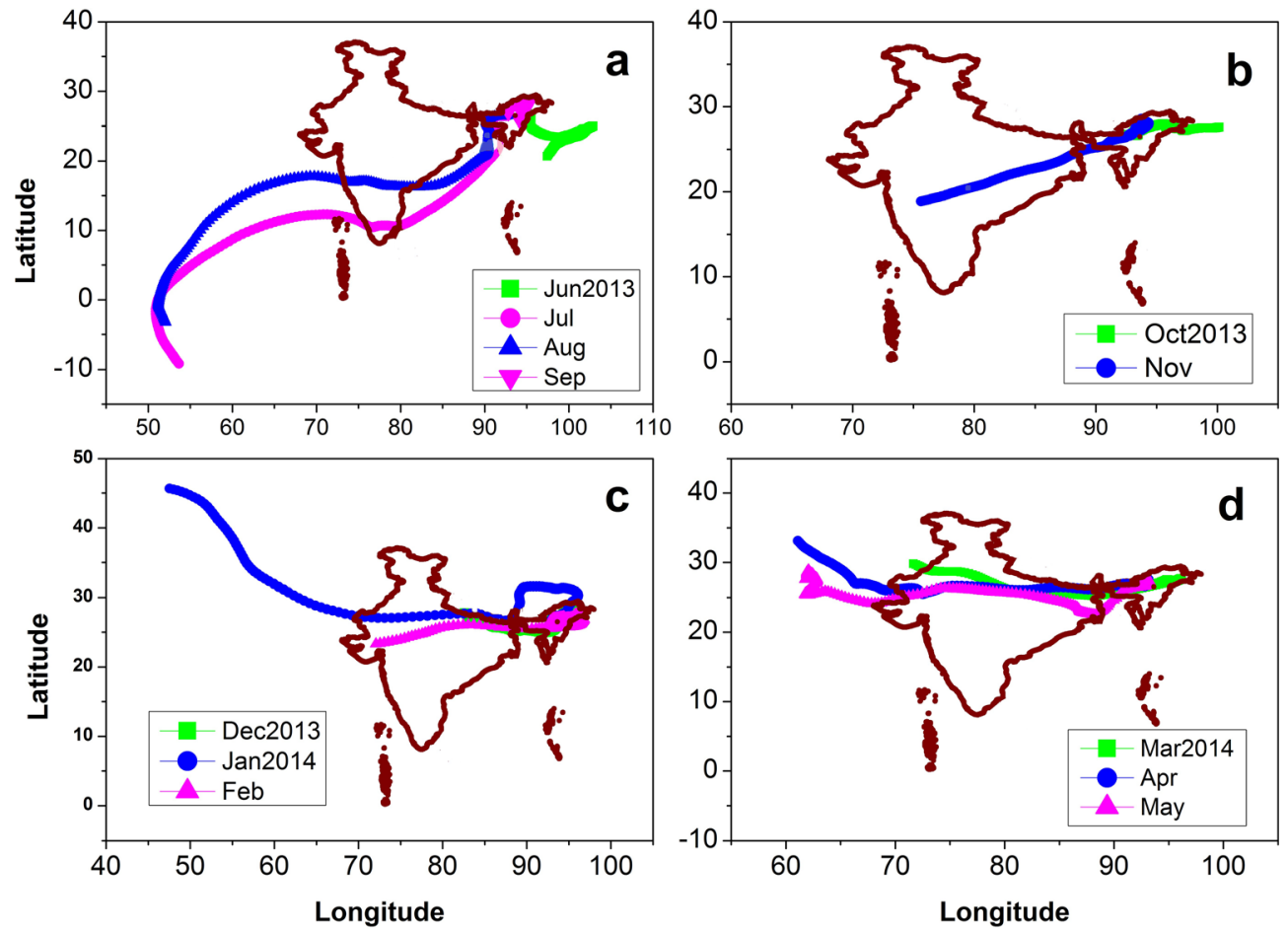

Figure 5

Back trajectories at $50 \mathrm{~m}$ above ground level obtained from HYSPLIT [Hybrid Single Particle Lagrangian Integrated Trajectory] using the Global Data Assimilation System (GDAS) at $0.5^{\circ}$ resolution with isobaric vertical velocity. Each trajectory extends 13 days starting on the 15 th of each month

(Published online November 6, 2020)

The original article can be found online at https://doi.org/10.1007/ s00024-020-02590-1.

1 Indian Institute of Tropical Meteorology, Dr Homi Road, Pune 411008, India. E-mail: murthy@tropmet.res.in 